\title{
"I Took the Trouble to Make Inquiries, So I Refuse to Accept Your Instructions": Religious Authority and Vaccine Hesitancy Among Ultra-Orthodox Jewish Mothers in Israel
}

\author{
Yael Keshet $^{1} \cdot$ Ariela Popper-Giveon $^{1}$
}

Accepted: 23 October 2020 / Published online: 2 January 2021

(c) Springer Science+Business Media, LLC, part of Springer Nature 2021

\begin{abstract}
Voluminous scholarship has shown that religious leaders play an important role in helping patients cope with health issues. There is, however, little research on the impact of religious leaders on parents' decision-making processes pertaining to childhood vaccination. Ultra-orthodox Jewish religious leaders (rabbis) are considered authorities on health issues, and most of them encourage parents to vaccinate their children. Yet, there have been several recent outbreaks of measles in the ultraorthodox population in Israel, as well as in other countries. The aim is to study the role played by rabbis in the decision-making process of Israeli ultra-orthodox Jewish parents with regard to vaccination. In-depth interviews were conducted during 2019 with ten Israeli ultra-orthodox Jewish mothers who do not vaccinate their children. The interviewees acknowledged that rabbis generally advocate vaccination. Yet they do not consult them and at times even disregard their instructions. The interviewees search for information on vaccination for themselves (mostly online) and decide not to vaccinate their children based on their assessment of risk. Contrary to the scholarly literature that points to the central role of religious leaders in dealing with health issues, the ultra-orthodox mothers' decision not to vaccinate their children appears to have been made despite the rabbis' instructions and not for religious reasons. These mothers' decision-making process is similar to that of mothers who do not vaccinate their children in other countries with respect to the aspect of gender, the search for information, and the reasons reported. Contacting the ultra-orthodox mothers directly and addressing their concerns about risk increase vaccination rates among the ultra-orthodox Jewish population.
\end{abstract}

Keywords Religious authority $\cdot$ Decision making · Vaccination · Children · Ultraorthodox $\cdot$ Israel

Yael Keshet

yaelk@wgalil.ac.il; yaelke@yvc.ac.il

1 Western Galilee College, Acre, Israel 


\section{Introduction}

\section{The Role of Religious Leaders in Coping With Health Issues}

People tend to turn to religion in general, and religious leaders in particular, to guide them when coping with health issues. In The Sociology of Religion, Max Weber (1985[1922]: 285ff) referred to the promise of salvation that religions offer in order to satisfy various psychological and social needs. Feelings of deprivation, misfortune and suffering lead the individual to search for compensation; he or she may seek a sign of salvation that promises release from misfortune or bodily healing in the near or distant future (Stolz 2008). In modern and post-modern societies as well, religion serves as a resource for dealing with existential and personal difficulties (Keshet and Liberman 2014a).

Nevertheless, while a large body of scholarship has documented the role of religion in coping with health issues broadly (e.g. Ahmadi and Ahmadi 2015; Lin et al. 2018; Santos et al. 2017), there is a paucity of literature pertaining to the part played by religion in healthcare decision making and all the more so in pediatric contexts (e.g. Malcolm et al. 2019). Several scholars have examined the role religious leaders play regarding parents' decisions to vaccinate their children specifically with human papilloma vaccine (HPV) (e.g. Fogel and Ebadi 2011; Shelton et al. 2013; Thomas et al. 2015), but only a few have discussed their role regarding the mandatory vaccination of children.

Understanding the role religious leaders play with regard to parents' decisions to vaccinate their children is of considerable importance. As Dubé and colleagues (2014) found in a qualitative study conducted among immunization managers from 13 different countries, religious beliefs often constituted a causal factor in vaccine hesitancy (cited by 9 of the 13 immunization managers). Several immunization managers pointed to specific religious groups in their country that were known to oppose all vaccines, while others cited "religious reasons" without specifying a certain religion or specific religious group.

In a systematic review, Jarrett and colleagues (2015) identified, described and assessed the potential effectiveness of various strategies employed to respond to vaccine hesitancy that have been implemented and evaluated across diverse global contexts. They concluded that the impact of religious or traditional leaders' involvement in populations with low vaccine uptake merits further investigation. They regard the religious or traditional leaders' involvement as important in addressing one of the determinants of vaccine hesitancy, namely misconceptions and community distrust. Such intervention aligns itself with natural community processes - seeking out community leaders and encouraging discussion with the population so as to inform and to influence.

While these studies point to the important role religious beliefs and religious leaders play in the decision-making process regarding vaccination, a closer look at the field reveals the unexpected phenomenon of religious people who do not follow the instructions of religious authority figures regarding mandatory vaccination of children. As we show in this paper, while ultra-orthodox Jewish 
religious leaders (rabbis) generally encourage parents to vaccinate their children, some ultra-orthodox Jewish mothers, such as those we interviewed, choose not to do so, in defiance of the religious authority's rulings.

\section{Ultra-Orthodox Jews, Religious Authority and Healthcare}

Ultra-orthodox Jews are considered the most devoted among religious Jews and are noted for their uncompromising adherence to the most stringent version of Jewish religious law (halacha). The Israeli ultra-orthodox Jewish community-which constituted 12\% of Israel's total population in 2018 (Israel Democracy Institute 2018) comprises diverse groups and subgroups that are subject to the guidance of their own religious and political leaders.

The ultra-orthodox Jewish religious leaders are esteemed rabbis whose moral authority and advice are customarily sought and unequivocally accepted (Latzer et al. 2019). Belief in the rabbis' knowledge and powers is deeply ingrained in Jewish culture, and rabbis are regarded as highly authoritative figures in the religious Jewish world. The rabbis lay down and maintain guidelines for behavior, issuing general public statements and responding to individual queries (Coleman-Brueckheimer et al. 2009). Keshet and Liberman (2014a) found that $24 \%$ of the general Israeli Jewish population regularly consult rabbis. Religious Jews (and ultra-orthodox Jews in particular) consult rabbis on a regular basis, inter alia on medical matters (Keshet and Liberman 2014b), in order to make sure that their actions accord with Jewish religious law.

Scholars have studied ultra-orthodox Jews' medical consultations with rabbis in the contexts of breast cancer (Coleman-Brueckheimer et al. 2009), fertility treatments and prenatal testing and pregnancy (Ivry 2010). Rabbinical advice was requested by parents of children with autism (Shaked and Bilu 2006); patients with eating disorders (Dancyger et al. 2002); patients with obsessive compulsive disorder (Greenberg and Shefler 2002); and those receiving genetic counseling (Mittman et al. 2007).

These consultations with rabbis vary widely in form. Some rabbis supply medications provided by charitable funds, commission specific practitioners to treat their community members, and have the final word on healthcare decisions. In some cases rabbinic intervention has been shown to include the "koshering" of medical care ("kosher" is a concept primarily used to designate the kinds of food that Jews may eat, but is extended here to denote approval of objects and procedures, including medical procedures) (Ivry 2010).

\section{Childhood Vaccination Among Ultra-Orthodox Jews in Israel}

The overall childhood vaccination coverage reported in Israel is consistently high (Israel Central Bureau of Statistics 2018). For example, children born between 2013 and 2015, reported compliance with the full vaccination program among children aged 0-2 years meet the WHO requirements, and are reported to be very high (97\%) among the total sample, with the highest rates found among ultra-orthodox Jews 
(98\%) (Elran et al. 2018). On the other hand, Stein-Zamir and Israeli (2019) investigated monitored vaccination completeness and timeliness specifically in Jerusalem, a district that experiences recurrent outbreaks of vaccine-preventable diseases. They found low vaccination coverage among the Jewish ultra-orthodox communities. Vaccination completeness and timeliness were higher among Arab children than among Jewish children, with the lowest rates found among children in Jewish ultraorthodox communities.

These findings point to the phenomenon of vaccine hesitancy, which has become more prevalent in Israel as in other countries during recent years. Vaccine hesitancy refers to a delay or refusal to vaccinate despite the availability of vaccination services. The phenomenon of vaccine hesitancy is complex and context-specific, varying across time, place, and type of vaccine (ECDC 2020). Maintaining vaccination uptake is vital if vaccines are to become effective. Therefore, the greater the prevalence of vaccine hesitancy, the lower becomes the vaccination rate, leading to insufficient "herd immunity" and a higher risk of "old disease" outbreaks (Jacobson et al. 2015).

Indeed, there have been several measles outbreaks in Israel in recent years (2003, 2004, 2007, 2013). During the most recent outbreak, between March 2018 until July 2019, 4,292 measles patients were reported. Most of these were children who had not been vaccinated at all, or whose vaccination status was unknown. Examination of the patients' home addresses revealed that the incidence of measles among the ultra-orthodox population was ten times higher than among the overall Israeli population. Thus, despite the high rate of first and second doses of measles vaccinations (about 96\%) in the general Israeli population (Israel Ministry of Health 2018), and a high rate of self-reported compliance with the full vaccination program among ultraorthodox Jews (98\%) (Elran et al. 2018), there are nevertheless "pockets" of low coverage, especially among certain groups within the ultra-orthodox population, in which the outbreaks occurred (Israel Ministry of Health 2018).

Describing rabbinic attitudes toward the mandatory vaccination of children, Turner (2017) highlighted the strong basis in Jewish religious law for the obligation to vaccinate children for vaccine-preventable diseases. In Jewish law, medical considerations of risk and safety are key to religious rulings regarding vaccination. In light of this orientation, the Orthodox Union (OU) and the Rabbinical Council of America (RCA), two large US rabbinic organizations, strongly urge vaccination in general, including mandatory childhood vaccines. According to the OU (Orthodox Union 2015) "Prayers must go hand in hand with availing oneself of medical science, including vaccination. There are halachic obligations to care for one's own health as well as to take measures to prevent harm and illness to others, and Jewish law defers to the consensus of medical experts in determining appropriate responses to illness and prevention. Therefore, the consensus of major poskim [religious adjudicators] supports the vaccination of children to protect them from disease, to eradicate illness from the larger community through so-called herd immunity, and thus to protect others who may be vulnerable."

Ultra-orthodox rabbis hence overwhelmingly support vaccination and instruct parents to vaccinate their children. One should therefore expect that ultra-orthodox Jewish parents would follow these instructions. Alas, despite the rabbis' instructions, 
there are still "pockets" of sub-optimal vaccination coverage within this population, among which epidemics break out.

The present research seeks to study the role attributed to the religious authority in the decision-making process of Israeli ultra-orthodox Jewish parents. Understanding the ultra-orthodox parents' decision-making process regarding vaccination is essential to cope better with sub-optimal coverage and subsequent epidemic outbreaks. Our findings are relevant not only to Israel but also to other countries home to ultra-orthodox Jewish communities in which epidemics occur. In New York, for example, measles outbreaks have likewise occurred among members of Brooklyn's ultra-orthodox Jewish community (Arciuolo et al. 2013; Tanne 2019; Wombwell et al. 2015).

\section{Methodology}

We conducted a qualitative study among Israeli ultra-orthodox Jewish mothers who declared that they do not vaccinate their children. We used snowball sampling, a method employed extensively in studies dealing with sensitive matters (Liamputtong 2007). We chose to reach out from one participant to another on a personal basis, relying on our existing social, professional, and familial network. We were thus able to build trust with individuals from the ultra-orthodox community, who are known to be suspicious and withdrawn from the general Israeli population, and at the same time to guarantee greater anonymity and alleviate fears of expressing one's views and experiences.

Scholars who use this convenient form of sampling initially select a few participants and ask them to recommend others who meet the designated criteria and may be willing to participate in the study. The designated criteria in the present study were "ultra-orthodox Jewish parents who declare that they do not vaccinate their children." Although we had intended to interview ultra-orthodox parents (mothers and fathers), only the mothers agreed to participate in the study. The interviews revealed that it was the mothers who made the decision not to vaccinate the children in their families, corroborating the well-documented assertion in the relevant literature that mothers are more involved than fathers in child healthcare (Moore and Kotelchuck 2004; Schoppe-Sullivan et al. 2008).

During 2019 in-depth interviews were conducted with ten Israeli ultra-orthodox Jewish women (aged 29-61; average age: 39), all of whom were married with children (2-12 children; on average: 6 ). The women belong to different groups within Israel's ultra-orthodox population: three are Lithuanians, four are Habad (Lubavitcher) hasidim, one is a Breslover hasid, one a Sephardi, and one a national ultra-orthodox. The participants live in Jerusalem (3) and its environs (2), ultraorthodox communities in the West Bank (3), and in the cities of Lod (1) and Beit Shemesh (1). All participants live in segregated ultra-orthodox communities or neighborhoods.

The 60-90-min-long interviews were conducted in Hebrew, a language in which all participants are fluent. Participants were asked an open question regarding their vaccination decision-making process and the impact that the rabbis' instructions 
had on it. We used a questionnaire designed specifically for this study. It included questions such as: What is your attitude toward vaccination? Has it changed over the years? Whom do you consult with on this matter? What sources of information do you rely on? After securing oral permission from the participants, interviews were taped and then transcribed verbatim and analyzed using Atlas.ti v7.5.17 textual analysis software for systematic coding and inductive analysis. Interviews were conducted by the second author, while analysis was carried out by both authors, who are secular Jews and who by and large favor vaccination. The research was approved by the Ethics Committee of Western Galilee Academic College and supported by its Research Authority.

\section{Findings}

According to the interviewees, the rabbis generally encourage vaccination and most of the ultra-orthodox population acts accordingly and vaccinates its children. The interviewees themselves, however, defy the rabbis' authority on this matter. Some avoid consultation with the rabbi, while others justify their non-compliance with the rabbi's instruction to vaccinate by interpreting his ruling differently. Moreover, they claim that the instruction to vaccinate does not fall within the area of rabbinical expertise and cannot be relied upon because the rabbis do not conduct their own investigation and place their trust in medical knowledge. Unlike the rabbis, the interviewees conducted a thorough investigation into the matter, gathering information from online sources and social media networks, books, healthcare professionals, and other sources. They concluded that vaccines entail considerable risk and in some cases have not undergone the requisite rigorous testing procedure. As a result, the interviewees declare that they are more afraid of the vaccines than of the diseases and have thus decided not to vaccinate their children.

\section{"We do Whatever the Rabbi Rules"-The Rabbis, in General, Call Upon People to Vaccinate}

The interviewees acknowledge that most ultra-orthodox parents in Israel vaccinate their children, contrary to the stigma associated with this population. They view this as naive, thoughtless behavior, explained by inadequate knowledge on the part of most of their community.

The ultra-orthodox population suffers from a stigma that they do not vaccinate. But unfortunately, the very opposite applies. Most of the ultra-orthodox people do vaccinate... and it hurts me because I feel that they are very naive... they trust the doctor's decisions, regarding vaccination as well. (Nehama)

They [ultra-orthodox people] ask no questions... If the doctor says you should vaccinate-they vaccinate. (Dvora)

According to the interviewees, most ultra-orthodox rabbis instruct parents to vaccinate their children. 
Most rabbis really support this [vaccination]... They listen to the doctors, believing vaccination is a healthy and appropriate step. (Sima)

The rabbis act in accordance with what they see as the public good. They are attentive to the advice given by medical professionals, who consider vaccination a means to promote public health, and may also hesitate to take responsibility for the consequences of non-vaccination.

During the measles' outbreak I kept seeing rabbis' statements calling [on people] to vaccinate... They instruct [parents] to vaccinate because they don't take responsibility for the community's health. (Shelly)

The ultra-orthodox parents, for the most part, comply with the rabbis' instructions and vaccinate their children.

Ultra-orthodox women say "we do whatever the rabbi rules," and the rabbi rules that we should vaccinate. I never heard of a rabbi who opposed it. (Ora)

\section{"I Don't Consult on Such Matters" — Interviewees Who Fail to Consult Their Rabbi or Even Defy his Instructions}

Although, as a rule, ultra-orthodox Jews obey their rabbis' rulings on all matters, the ultra-orthodox mothers we interviewed defy the rabbis' instructions to vaccinate children. One of the interviewed mothers, for example, explained that she refrained from consulting the rabbi about vaccination, knowing that she would in fact disobey him.

Actually, I consult the rabbi a lot, why didn't I consult him this time?... I saw that the rabbis unequivocally instruct [people] to vaccinate... so I knew that if I were to consult him-I would have to vaccinate. (Shelly)

Shelly explains that she herself decided against vaccinating her children, and did not consider the matter important enough to consult the rabbi.

I do not consult [the rabbi] regarding such things... It seems like a personal decision to me... It seemed too simple to ask... I think I consult on health issues when I have doubts... and in this case I don't have any doubts. (Shelly)

Some of the interviewees not only refrain from consulting the rabbi regarding their children's vaccination to avoid having to disobey his instructions, but they knowingly defy the rabbis' rulings.

There was, for example, a rabbi's ruling... He said that we all should vaccinate, but I said to myself... If the rabbi doesn't investigate the subject himself... he can't rule on something he hasn't tested... I took the trouble to make inquiries, so I refuse to accept your instructions. (Ora) 


\section{"I am Much More Afraid [of the Consequence of Vaccination] Than of [Being] Unable to Comply With the Rabbi's Instructions"—Justifications for Defying the Rabbi's Rulings Regarding Vaccination}

In order to bridge the gap between the rabbinic imperative and their actual behavior, the interviewees offered three different justifications. These justifications are reiterated by the women who belong to the Habad Hasidim, since their renowned leader, Rabbi Menachem Schneerson ("the Lubavitcher"), who passed away in 1994, published letters that clearly support vaccination (Turner 2017).

First, the interviewees offered their own interpretation of the rabbi's rulings. They tend to disregard the rabbi's statements that favor vaccination of children and cite other messages articulated by the rabbi that could justify their decision not to vaccinate. In order to justify the discrepancy between the Lubavitcher Rabbi's imperatives and their actual actions, some of the interviewees emphasize his implicit call to make an informed decision on medical matters.

I saw a letter from the rabbi, writing about another matter... He instructed a man who was supposed to take antibiotics to check it out well because medical knowledge is constantly updating and the doctor, since he's so busy, doesn't have the time to check out the new studies... So, one shouldn't just do what the doctor says, but should check it out well before doing so. I perceived this as a milestone, here the rabbi tells us to catch up, to check what's going on. (Hana)

Other interviewees explain that the rabbi's rulings should be viewed in a fresh light, mainly since children nowadays receive more vaccines than in the past.

The Lubavitcher Rabbi is the authority... He ruled, "when it comes to vaccination, one should not cut oneself off from the general public... and it really hurts [me] because I do want to obey the rabbi... So, I searched for the original text, from the 1950s. There were perhaps three vaccines given back then. (Sima)

Second, the interviewees claim that since the rabbis are not experts in vaccination and have not investigated the subject themselves, they are not required to accept their authority on this specific matter.

They [the rabbis] instruct [us] to vaccinate without researching it... In medicine, doctors are the experts. An ENT doctor is not an expert in oncology... everyone has his own expertise. (Nehama)

Third, the interviewees explain that they made the decision not to vaccinate their children following a thorough investigation of the subject. The majority found relevant information about vaccination online and specifically on social media networks.

[I look for information] on the internet, that is, in the vaccination forums and on YouTube... Lectures by conventional doctors who used to vaccinate and then discovered something... I am interested to hear what they have to say. (Sima) 
I also read a lot about it, and I watched many videos... What it [vaccination] is exactly, what it does and how it damages... Some on Facebook and some on WhatsApp... I participate in a Facebook group for parents who do not vaccinate, called 'Vaccines-Educated Choice'... where people share information. (Hana)

Some of the interviewees consult with various health professionals and others they trust. They also search for information regarding vaccination in books.

I checked what the vaccines contain. I also talked to nurses in the infants clinic, though they don't know much... I read a book about vaccination. I just search and search wherever I can, and ask people I trust. (Sara)

Their investigation revealed that vaccination, in their view, was not a protective measure and entailed considerable risk. The interviewees claim that vaccines can bring on severe conditions such as epilepsy and autism, and may even cause death.

I have a four-year-old nephew who was diagnosed with epilepsy half a year ago. I have no doubt that vaccines are involved... I know from my research that epilepsy is one of the problems caused by vaccination. (Lea)

Vaccines insert things into our bodies that endanger our children's health... In Israel, half a million children are reported to be on the [autistic] continuum, from ADHD to autism, as a result of vaccines. (Naama)

I keep coming across stories of parents whose children were damaged after receiving a vaccine. Some are not even aware of it. The sudden infant death syndrome, for example, always strikes at two months, at four months, shortly after receiving a vaccine. (Sima)

Moreover, according to the interviewees, in some cases vaccines were found not to have undergone the requisite rigorous testing procedure, perhaps because dark economic interests are at play.

There are no studies that prove the safety [of vaccines], as there should be... If you are testing a drug for pregnant women-you should carry out the research on pregnant women... [If] you are testing a baby's vaccine-you have to conduct the research on the relevant population. (Na'ama)

Between 2011 and 2015... The hepatitis vaccine manufactured in Israel was given [to babies] on the first day... at the age of one month and at the age of six months... This vaccine was not approved and did not pass through stage three trials... In 2015 they had a recall; they said that some bottles were broken, that there were cracks... this is very bad, since bacteria may have penetrated them. (Sima)

I'm sure everything there is one big deal of money. (Sara)

According to the interviewees, vaccines are perceived as dangerous, even more dangerous than the disease they are supposed to prevent.

How can I know for sure what will be injected into my child?... I am much more afraid [of the consequence of vaccination] than... [of being] unable to 
comply with the rabbi's instructions... I realized that I'm much more afraid of the vaccines than of the diseases. (Sima)

When I decided not to vaccinate my youngest child, I was indeed a little frightened but I was more afraid of the vaccines. (Naama)

The interviewees are indeed aware of the risks of vaccine-preventable infectious diseases, but are convinced that their children are healthier for not being vaccinated and can withstand the diseases.

[We give] no vaccine; no hesitation at all... it's actually not just the vaccines, it's the entire approach... that basically the causes of the diseases are not the bacteria and viruses so there is no point in fighting them. As if the whole point of vaccines is basically to stop the viruses, and all that. Since we believe they do not cause the diseases, there is no point in messing with it (Hana).

She [her daughter] contracted jaundice at the hospital and after a few days, three four days, suffered from severe breathlessness... The girl is not breathing! Not breathing!... I consulted doctors, ran to hospitals for about two and a half years... I cried night and day. It was awful and I did not link it in any way to the vaccine. I didn't know... and yet I was afraid not to vaccinate... I was scared. Then, during my fourth pregnancy, I started reading and researching and checking... Thank God the little child hasn't been vaccinated. Thank God. She is vaccinated by the Blessed One from age zero (Lea).

\section{Discussion}

This paper should be viewed in the more general context of the enduring religion and science-anti-science discourse (e.g., Ecklund and Scheitle 2017; Harrison 2015). Science permeates all aspects of life in modern society. Anti-science, on the other hand, depending on its scope, may weaken public trust in the knowledge that science produces. Anti-science sentiments may undermine public and individual support for science and may promote negative attitudes toward science and scientific medicine (Gauchat 2008).

Gauchat (2008) offers three explanations of the growth of anti-science: the lack of scientific knowledge engenders anti-science attitudes; strong religious beliefs are the primary impetus of anti-science attitudes; and anti-science attitudes can be traced to an individual's social circumstances. These three explanatory factors help to explain the present findings as well.

By and large, the Israeli ultra-orthodox leadership encourages its flock to listen to physicians and vaccinate their children. Thus, it was not their strong religious belief that drove the ultra-orthodox mothers we interviewed not to vaccinate their children. Rather, the factors that impacted their decision were their unique individual social context, the influences of their networks and social ties, which shape individuals' attitudes toward science. Our findings, like those of Gauchat (2008), indicate that trust, perceptions about societal values, and social ties (what sociologists often refer to as social capital) affect individuals' sentiments toward science. This can be inferred from the similarity between the decision-making 
process among Israeli ultra-orthodox Jewish mothers who do not vaccinate their children and that among non-vaccinating secular mothers in other countries.

Our research reveals that the decision-making process of Israeli ultra-orthodox Jewish mothers who do not vaccinate their children is similar to that of non-vaccinating secular mothers in other countries. First, with regard to the sources of information on which they rely, specifically online sources; second, with regard to their motives for not vaccinating their children, mainly concerns about the risk associated with vaccines; and third, with regard to the gender issue that the mothers, rather than the fathers, are those who make the decision not to vaccinate the children.

According to the interviewees, their main source of information about vaccination is the internet and specifically the social media networks. They either consult people to gain online information, or search for information themselves online. This is an interesting finding given that previous studies found that ultra-orthodox people are less connected to the internet than the general population of Israel (Israel Democracy Institute 2018).

Nowadays, vaccine hesitancy is closely connected to the growing influence of the internet and the new information and communication technologies (Tafuri et al. 2014), which play an important role in parents' decisions on whether or not to vaccinate their children (Rosselli et al. 2016). Over the past decade, anti-vaccination rhetoric, which has become part of the mainstream discourse regarding childhood vaccination, utilizes the social media to promote and popularize anti-vaccination discourses (Smith and Graham 2019).

While ultra-orthodox Jews are characterized by social withdrawal from what they perceive as "the dangers of modern society," the mass media, especially the internet, presents a major challenge to their self-isolation (Cohen 2016). Today, more and more ultra-orthodox Jews own computers and some are connected to the internet. One of the major consequences of this process is the erosion of rabbinical hegemony (Cohen 2017).

The second similarity between the ultra-orthodox mothers we interviewed and other mothers who do not vaccinate their children can be found in their motives. Both the interviewees in this study and non-vaccinating mothers mentioned in other studies declare that the main motive for not vaccinating their children was their belief that vaccines are more dangerous than the diseases they are supposed to prevent. Non-vaccinating parents believe that vaccines are toxic and may produce a variety of illnesses and adverse conditions, including autism (Smith and Graham 2019).

The motives for not vaccinating their children are therefore similar among the ultra-orthodox mothers we interviewed and among other non-vaccinating mothers. They are mainly associated with notions of risk that derive from information gleaned from online sources. Vaccination, in the interviewees' view, is not a protective step but rather a dangerous one. They claim that vaccines lead to conditions such as epilepsy and autism. Furthermore, they argue, some vaccines were found not to have undergone the requisite rigorous testing procedure. In other words, vaccines that are supposed to protect children from life-threatening diseases are in fact themselves perceived as dangerous and life-threatening. 
Similarly, those among the non-vaccinating community harbor grave concerns pertaining to institutional vested interests perceived to be perpetuating the harmful practice of vaccination. They hold conspiracy-style beliefs, according to which the government and media are key actors in underplaying, denying and perpetuating the perceived harm done by vaccinations (Smith and Graham 2019).

A further similarity that emerges upon comparing the ultra-orthodox mothers interviewed in this study with the research literature on vaccine hesitancy is that of gender. Our research reveals that mothers are the ones who usually make the decision not to vaccinate their children.

Smith and Graham (2019), who examined the characteristics of the discourses prevalent on six popular English language anti-vaccination Facebook pages, found that the majority of those within the anti-vaccination movement who post on Facebook are female, and that women constitute an even greater proportion of the most active users. The anti-vaccination movement is now primarily led by women. This gender imbalance reflects dominant cultural understandings of parenting; namely, that the parenting and care of children is primarily a maternal concern (Smith and Graham 2019).

\section{Conclusions}

The decision by ultra-orthodox Jewish mothers not to vaccinate their children is made in contravention of the rulings of their religious authority and is not associated with religious motives. Both their process of information gathering and their motives for not vaccinating their children are similar to those of other mothers worldwide. While the ultra-orthodox mothers obey the religious authority, the rabbis, on most matters, when deciding whether or not to vaccinate their children they rely primarily on the information they find online and defy the rabbis' explicit instructions.

\section{Recommendations}

Public health authorities should address ultra-orthodox mothers directly and not only through the rabbis, on the assumption that their instructions to vaccinate will convince all their flock and will thus increase vaccination coverage. When interacting with ultra-orthodox mothers, safety considerations should be highlighted and well-substantiated data should be provided in order to increase vaccination coverage among the ultra-orthodox Jewish population.

\section{Limitations of the Research}

The main limitation of the present research is the small number of participants interviewed. While this small sample has facilitated deeper insights, our conclusions await support from a larger study. Another limitation is the focus on participants who declare that they do not vaccinate their children. Future studies could include 
hesitant parents alongside those who vaccinate their children, in order to understand better the decision-making process surrounding vaccination, the means of information gathering, and the motives for acting one way or another.

\title{
Compliance with Ethical Standards
}

\author{
Conflict of interest No conflict of interest.
}

Ethical Approval The study protocol was approved by the Ethics Committee of Western Galilee Academic College.

Informed Consent All participants were given information on the study and agreed to participate on a voluntary basis. All names used in this manuscript are pseudonyms.

\section{References}

Ahmadi, F., \& Ahmadi, N. (2015). Nature as the most important coping strategy among cancer patients: A Swedish survey. Journal of Religion and Health, 54(4), 1177-1190.

Arciuolo, R. J., Brantley, T. R., Asfaw, M. M., Jablonski, R. R., Fu, J., Giancotti, F. R., \& Zucker, J. R. (2013). Measles outbreak among members of a religious community-Brooklyn, New York, March-June 2013. Morbidity and Mortality Weekly Report, 62(36), 752.

Cohen, Y. (2016). Haredim and the internet: A hate-love affair. In M. Baily \& G. Redden (Eds.), Mediating faiths: Religion and socio-cultural change in the twenty-first century (pp. 63-71). Ashgate Publishing.

Cohen, Y. (2017). The media challenge to haredi rabbinic authority in Israel. Journal for Communication Studies, 10(02), 113-128.

Coleman-Brueckheimer, K., Spitzer, J., \& Koffman, J. (2009). Involvement of rabbinic and communal authorities in decision-making by haredi Jews in the UK with breast cancer: An interpretative phenomenological analysis. Social Science and Medicine, 68(2), 323-333.

Dancyger, I., Fornari, V., Fisher, M., Schneider, M., Frank, S., Wisotsky, W., et al. (2002). Cultural factors in orthodox Jewish adolescents treated in a day program for eating disorders. International Journal of Adolescent Medical Health, 14(4), 317-328.

Dubé, E., Gagnon, D., Nickels, E., Jeram, S., \& Schuster, M. (2014). Mapping vaccine hesitancy: Country-specific characteristics of a global phenomenon. Vaccine, 32(49), 6649-6654.

ECDC (2020). Vaccine hesitancy. https://www.ecdc.europa.eu/en/immunisation-vaccines/vaccine-hesit ancy. Accessed 11/10/2020.

Ecklund, E. H., \& Scheitle, C. P. (2017). Religion vs. science: What religious people really think. Oxford: Oxford University Press.

Elran, B., Yaari, S., Glazer, Y., Honovich, M., Grotto, I., \& Anis, E. (2018). Parents' perceptions of childhood immunization in Israel: Information and concerns. Vaccine, 36(52), 8062-8068.

Fogel, J., \& Ebadi, C. (2011). Religious categories and the human papillomavirus (HPV) vaccine: Attitudes, intentions, and behaviors regarding vaccination. Journal of Medical Marketing, 11(4), 303-311.

Gauchat, G. W. (2008). A test of three theories of anti-science attitudes. Sociological Focus, 41(4), 337-357.

Greenberg, D., \& Shefler, G. (2002). Obsessive compulsive disorder in ultra-orthodox Jewish patients: A comparison of religious and nonreligious symptoms. Psychology and Psychotherapy: Theory, Research and Practice, 75, 123-130.

Harrison, P. (2015). The territories of science and religion. Chicago: University of Chicago Press.

Israel Central Bureau of Statistics (2018). Statistical Abstract of Israel 2018, No.69. Children immunized out of those registered in the mother and infant centers. Jerusalem: CBS; 2018. Available from: https://www.cbs.gov.il/he/publications/doclib/2018/6.\%20shnatonhealth/st06_12.pdf 
Israel Democracy Institute (2018). Yearbook of Haredi society. https://www.idi.org.il/media/11852/hared im-2018-summary.pdf [Hebrew] [accessed 18 August 2019]

Israel Ministry of Health (2018). Summary of infectious disease and vaccination advisory committee meeting concerning the outbreak of measles, 23 October. https://www.health.gov.il/Services/Commi ttee/IDAC/Documents/CSV_23102018_2.pdf [Hebrew] [accessed 18 August 2019]

Ivry, T. (2010). Kosher medicine and medicalized halacha: An exploration of triadic relations among Israeli rabbis, doctors, and infertility patients. American Ethnologist, 37(4), 662-680.

Jacobson, R. M., St Sauver, J. L., \& Finney Rutten, L. J. (2015). Vaccine hesitancy. Mayo Clinical Proceedings, 90(11), 1562-1568.

Jarrett, C., Wilson, R., O’Leary, M., Eckersberger, E., \& Larson, H. J. (2015). Strategies for addressing vaccine hesitancy-a systematic review. Vaccine, 33(34), 4180-4190.

Keshet, Y., \& Liberman, I. (2014a). Seeking empowerment and spirituality in the secular age: Secular and traditionalist Israelis consulting rabbis. Sociology, 48(1), 92-110.

Keshet, Y., \& Liberman, I. (2014b). Coping with illness and threat: Why non-religious Jews choose to consult rabbis on healthcare issues. Journal of Religion and Health, 53(4), 1146-1160.

Latzer, Y., Stein, D., \& Witztum, E. (2019). Treating ultra-orthodox adolescents with eating disorders in Israel: Culturally sensitive interventions, difficulties and dilemmas. Journal of Clinical Psychology, $75,1455-1468$.

Liamputtong, P. (2007). Researching the vulnerable: A guide to sensitive research methods. London: Sage.

Lin, C. Y., Saffari, M., Koenig, H. G., \& Pakpour, A. H. (2018). Effects of religiosity and religious coping on medication adherence and quality of life among people with epilepsy. Epilepsy and Behavior, 78, $45-51$.

Malcolm, H. V., Desjardins, C. M., Ferrara, B., Kitamura, E. A., Mueller, M., Betz, J., et al. (2019). Parental use of religion and spirituality in medical decision-making. Journal of Health Care Chaplaincy. https://doi.org/10.1080/08854726.2019.1670566

Mittman, I. S., Bowie, J. V., \& Maman, S. (2007). Exploring the discourse between genetic counselors and orthodox Jewish community members related to reproductive genetic technology. Patient Education and Counseling, 65, 230-236.

Moore, T., \& Kotelchuck, M. (2004). Predictors of urban fathers' involvement in their child's health care. Pediatrics, 113, 574-580.

Orthodox Union (2015). Statement on vaccinations from the OU and Rabbinical Council of America. https://www.ou.org/news/statement-vaccinations-ou-rabbinical-council-america/

Rosselli, R., Martini, M., \& Bragazzi, N. L. (2016). The old and the new: Vaccine hesitancy in the era of the Web 2.0. Challenges and opportunities. Journal of Preventive Medicine and Hygiene, 57(1), $47-50$.

Santos, P. R., Junior, J. R. F. G. C., Cavalcante Filho, J. R. M., Ferreira, T. P., dos Santos Filho, J. N. G., \& da Silva Oliveira, S. (2017). Religious coping methods predict depression and quality of life among end-stage renal disease patients undergoing hemodialysis: A cross-sectional study. $B M C$ Nephrology, 18(1), 197.

Schoppe-Sullivan, S. J., Brown, G. L., Cannon, E. A., Mangelsdorf, S. C., \& Sokolowski, M. S. (2008). Maternal gatekeeping, coparenting quality and fathering behavior in families with infants. Journal of Family Psychology, 22(3), 389-398.

Shaked, M., \& Bilu, Y. (2006). Grappling with affliction: Autism in the Jewish ultraorthodox community in Israel. Culture, Medicine and Psychiatry, 30, 1-27.

Shelton, R. C., Snavely, A. C., De Jesus, M., Othus, M. D., \& Allen, J. D. (2013). HPV vaccine decision-making and acceptance: Does religion play a role? Journal of Religion and Health, 52(4), $1120-1130$

Smith, N., \& Graham, T. (2019). Mapping the anti-vaccination movement on Facebook Information. Communication and Society, 22(9), 1310-1327.

Stein-Zamir, C., \& Israeli, A. (2019). Timeliness and completeness of routine childhood vaccinations in young children residing in a district with recurrent vaccine-preventable disease outbreaks, Jerusalem, Israel. Eurosurveillance. https://doi.org/10.2807/1560-7917.ES.2019.24.6.1800004

Stolz, J. (2008). Salvation goods and religious markets: Theory and applications. Frankfurt am Main: Peter Lang.

Tafuri, S., Gallone, M. S., Cappelli, M. G., Martinelli, D., Prato, R., \& Germinario, C. (2014). Addressing the anti-vaccination movement and the role of HCWs. Vaccine, 32, 4860-4865.

Tanne, J. H. (2019). New York city mayor declares measles public health emergency. BMJ, 365, 11724. 
Thomas, T., Blumling, A., \& Delaney, A. (2015). The influence of religiosity and spirituality on rural parents' health decision-making and human papillomavirus vaccine choices. Advances in Nursing Science, 38(4), E1.

Turner, A. (2017). Jewish decisions about childhood vaccinations: The unification of medicine with religion. Paediatrics and Health, 5(1), 1.

Weber, M. (1985[1922]). Wirtschaft und Gesellschaft. Tubingen: J.C.B. Mohr.

Wombwell, E., Fangman, M. T., Yoder, A. K., \& Spero, D. L. (2015). Religious barriers to measles vaccination. Journal of Community Health, 40(3), 597-604.

Publisher's Note Springer Nature remains neutral with regard to jurisdictional claims in published maps and institutional affiliations. 